ZOOLOGIA 30 (4): 424-429, August, 2013

http://dx.doi.org/10.1590/S1984-46702013000400008

\title{
Allometry as evidence of sexual selection in monochromatic birds: the case of the Coscoroba Swan (Anseriformes: Anatidae)
}

\author{
Cecilia P. Calabuig1', Andy J. Green², Roberto Muriel'3, Marco Katzenberger ${ }^{4}$, \\ Juan Patino-Martinez ${ }^{3} \&$ Heden M. Moreira ${ }^{5}$
}

\author{
${ }^{1}$ Departamento de Ciências Animais, Laboratório de Gestão e Conservação de Fauna Silvestre, Universidade Federal Rural do \\ Semiárido. Avenida Francisco Mota 572, 59625-900 Mossoró, RN, Brazil. E-mail: cecicalabuig@ufersa.edu.br \\ ${ }^{2}$ Departamento de Ecologia de Humedales, Estación Biológica de Doñana, Consejo Superior de Investigaciones Científicas. \\ Avenida Américo Vespúcio, 41092 Sevilla, Spain. \\ ${ }^{3}$ Departamento de Etologia y Conservación de la Biodiversidad, Estación Biológica de Doñana, Consejo Superior de Investigaciones \\ Científicas. Avenida Américo Vespúcio, 41092 Sevilla, Spain. \\ ${ }^{4}$ Departamento de Ecologia Evolutiva, Estación Biológica de Doñana, Consejo Superior de Investigaciones Científicas. \\ Avenida Américo Vespúcio, 41092 Sevilla, Spain. \\ ${ }^{5}$ Laboratório de Engenharia Genética Animal, Departamento de Zoologia e Genética, Universidade Federal de Pelotas. \\ Campus Universitário, 96010-900 Pelotas, RS, Brazil.
}

\begin{abstract}
The Coscoroba Swan, Coscoroba coscoroba (Molina, 1782), is a poorly known aberrant Anserine endemic to South America. We captured adult birds (189 male, 157 female) from the largest population in Brazil at the Taim Ecological Reserve, State of Rio Grande do Sul, Brazil. Different patterns between sexes can reflect differences in selection, and positive allometry may indicate that a character is sexually selected. We used body weight and 10 morphological measurements to examine allometric differences between males and females of $C$. coscoroba. Males were consistently larger than females. Analysis of scaling relationships against body mass showed that nostril, tail, wing and bill height were positively allometric (i.e., heavier birds had relatively larger character lengths), but there were no sexual differences in allometric slopes. However, for a given mass, mature females had longer tails, longer wings (up to metacarpophalangeal articulation) and shorter heads than males. In the light of current debate in the literature, we discuss whether such positively allometric traits and sexual differences in scaling may be indicative of sexual selection. Although Coscoroba Swan is a monogamous species, increasing the size of some attributes may confer some advantage for mate selection or male-male competition and, contrary to other studies, we suggest that positively allometric slopes alone should not be considered as evidence for sexual selection of the considered traits.
\end{abstract}

KEY WORDS. Monomorphic; natural selection; waterfowl, scaling.

The "allometry" or "scaling" of morphological characters in vertebrates has long been a subject of interest (Gould 1966, Reiss 1991). However, we still have relatively little understanding of the relationship between static allometry, or variation in shape among individuals of the same species and developmental stage, and sexual dimorphism (GreEN 2000, BONDURIANSKY 2007, CUeRVo \& MølLER 2009). Using standard morphological measurements, the relative variation of each character in relation to a reference body size measurement may be compared in order to examine scaling patterns within and between sexes. Characters subjected to strong sexual selection in a given sex are expected to be exaggerated in size, leading to sexual dimorphism, but are also likely to be positively allometric (i.e., larger individuals have even larger attributes than expected from their body size - GreEN 1992, 2000, KODRIC-Brown et al. 2006).
Recent studies have indicated that positive allometry does not seem to be a reliable indicator of sexual selection and have shown variable scaling relationships for characters thought to be sexually selected (e.g., Bonduriansky 2007, Cuervo \& Møller 2009). In fact, the scaling parameter for a certain character reflects the trade-offs between resource allocation, natural selection and sexual selection, and thus directional selection of sexual traits does not necessarily lead to positive allometry (BONDURIANSKY 2007). However, more studies on scaling relationships for traits lacking extreme exaggeration are necessary in order to evaluate the connection among relative variation of morphological traits, functional responses and evolutionary consequences, both for secondary sexual and non-sexual characters (BONDURIANSKY 2007).

The Coscoroba Swan, Coscoroba coscoroba (Molina, 1782) is unusual among the Anatidae in South America, and is found 
from the Falkland Islands and Tierra del Fuego north through Chile and Argentina, Uruguay and southern Brazil and Paraguay (KEAR 2005). The Coscoroba is traditionally considered to be a swan, but molecular studies suggest it is more closely related to the aberrant Cape Barren goose, Cereopsis novaehollandiae Latham, 1802 (see DonNe-Goussé et al. 2002). It is monochromatic, but males are generally larger than females (see below and Calabuig et al. 2011).

In monogamous species, such as the C. coscoroba, sexual dimorphism is often less exaggerated than in related polygamous species (e.g., Figuerola \& Green 2000, Horrocks et al. 2009). Yet, in species with high levels of parental care and variability in quality of partners, mutual mate choice is typically important (Clutton-Brock \& Vincent 1991, Clutton-Brock \& Parker 1992, Johnstone et al. 1996, KraAjeveld et al. 2004). Like true swans, the Coscoroba Swan displays high levels of parental care, but unlike true swans (KraAijeveld et al. 2004) it does not have obvious secondary sexual characteristics, and very little is known about the ecology of the species (see KeAR 2005, Calabuig et al. 2010).

The objective of this study was to investigate the relationship between sexual dimorphism and static allometry in the Coscoroba, in particular: a) to identify characters that were sexually dimorphic, before and after controlling for general structural size, and b) to compare allometric slopes for different characters between the sexes, and to identify positively allometric characters. We also examine the role that sexual selection may have in explaining our results.

\section{MATERIAL AND METHODS}

All individuals were captured at the "Estação Ecológica do Taim" Reserve which is located in the southern coastal plain of Brazil $\left(\sim 32^{\circ} 33^{\prime} \mathrm{S}, 52^{\circ} 32^{\prime} \mathrm{W}\right)$ within the most important area for Coscoroba Swan in Brazil. Birds were captured by hand, from a boat, in 2005, 2006, 2007, and 2008, during the wing moult period (between August and January), when they are flightless. All the individuals considered in our analysis were mature ( $>2$ years old). We captured 346 individuals (189 males, 157 females).

We weighed the birds (50 g precision) and measured 10 morphological variables. Total length of head to the occipitaltip of the bill (TLH), maximum height of the bill (HBI), maximum width of the bill (WBI), nostril (distal edge of a nostril to the end of the bill), total culmen (TCU) and tarsus length were measured with a calliper $( \pm 0.1 \mathrm{~mm})$. Tail (from the preen gland), wing without the feathers (metacarpophalangeal articulation), forearm length from the front of the folded wrist to the proximal extremity of the ulna (Ferrer \& De Le Court 1992) and length of neck (LNE) were measured with a ruler marked in millimetres.

Before releasing, the tarsus of each animal was marked with a numbered, metal ring (rings from Centro Nacional de
Pesquisa para Conservação das Aves Silvestres - Instituto Chico Mendes de Conservação da Biodiversidade (CEMAVE-ICMBio)).

Three milliliters of blood were taken from the wing vein of each bird, (using plastic $3 \mathrm{ml}$ syringes equipped with 21-ga needles) and samples were stored in Vacutainer tubes with EDTA and kept cool in ice, until processing. We used molecular methods to determine the sex of each specimen (see Calabuig et al. 2011 for details).

To compare sexes, we used all 11 morphological variables in a multivariate ANOVA (MANOVA). We used residuals from each analysis to check the normality assumption. None of the 11 variables showed significant deviation from normality according to the Kolmogorov-Smirnoff test with Lilliefor's correction, or from homogeneity of variance tested with Levene's test. Consequently, no transformations were used.

Length of neck (LNE) was excluded from further analyses due to a large measurement error. Following the standard approach in scaling studies (e.g., Green et al. 2001, WarTon et al. 2006, Arnold \& Green 2007, Peig \& Green 2009), the allometric slopes of each linear measure in relation to mass were calculated using reduced major axis (RMA, also known as standardised major axis or SMA) regression models to place the line of best fit in bivariate plots of log transformed data. The results of ordinary least squares regression (OLS) and RMA regressions are increasingly divergent as $r$ decreases, and slopes become seriously underestimated by OLS methods (MCARdLE 1988, Warton et al. 2006, Arnold \& Green 2007). The RMA slope is equal to the ratio between the standard deviations of $\mathrm{Y}$ and $\mathrm{X}$ (and also to the OLS slope divided by r). See McArdLE (1988) for methods used to calculate the statistical significance of the deviation between observed RMA slopes and those expected under the null hypothesis of isometry. For the purpose of this paper, we consider isometry to be where, in log-log bivariate plots, linear measures scale with a slope of one third against mass (i.e., mass is proportional to the cube of length). Since slopes did not differ significantly between males and females (see below), sexual differences in elevation (i.e., intercepts) were tested by comparing the means of the residual scores for each sex from a common RMA regression slope (see WARTON et al. 2006). This constituted a test for a difference between sexes in the relative size of different characters. We preferred this test to least-squares methods such as ANCOVA owing to the existence of error in both dependent and predictor variables (see WARTON et al. 2006).

Statistical analyses were carried out with Statistica 6.0 software (Statsoft Inc., Tulsa). Differences were considered significant at $\mathrm{p}<0.05$.

\section{RESULTS}

Using all variables in a MANOVA, adult male swans are larger than adult females (Wilks $=0.29, \mathrm{~F}=77.7, \mathrm{p}<0.01$ ). Values of body mass and all linear measures were significantly 
higher for males than females (Table I). TLH, tarsus and forearm were the most sexually dimorphic characters in terms of statistical significance.

RMA regression with body weight, nostril, wing and tail length showed significant positive allometry for both sexes (Table II and Figs 1-3). For mature males, HBI also showed significant positive allometry. However, no significant difference was observed in allometric slopes between the sexes for any morphometric measures (Table II).

When common slopes were fitted for all mature birds in regressions of linear measures on body mass, there were differences in elevation between sexes for three measures. For a given body mass, females had lower TLH but longer wings and longer tails (Table III, Figs 2 and 3).

\section{DISCUSSION}

Our results indicate interesting deviations from isometry in C. coscoroba, with nostrils, tails and wings showing positive allometry. Important differences in scaling relationships were also found among females and males. For a given body mass, the wing and tail of females were relatively larger, whereas their heads were comparatively shorter. All morphometric measurements showed a clear dimorphism according to gender and followed a size gradient in which male characters were, on average, larger than their corresponding female counterparts.

Miller et al. (1988) suggested for Tundra swans, Cygnus columbianus (Ord, 1815) that similar dimorphism among adult birds is the result of selection for large body size in males. In general, large size may be selected in male swans, geese and the Cape Barren Goose because they are responsible for nest

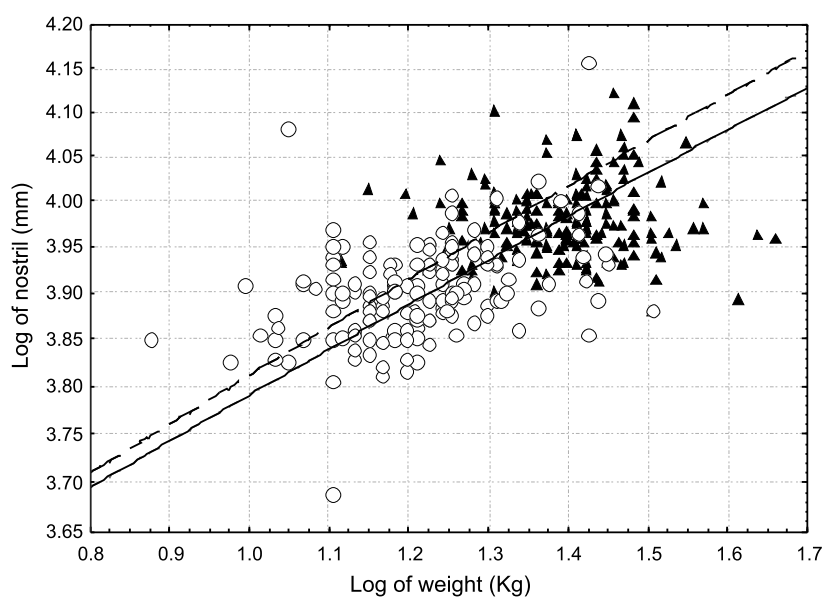

Figure 1. Nostril length against mass ( $\log _{e}$ transformed) for male and female Coscorobas. Scaling lines are plotted for both sexes using RMA regression (females: $y=3.3+0.512^{*} x$, males: $y=$ $\left.3.31+0.481^{*} x\right)$. The slopes and elevations were not different between sexes (Tables II and III). (O) Females, ( $(\mathbf{\Delta})$ males.

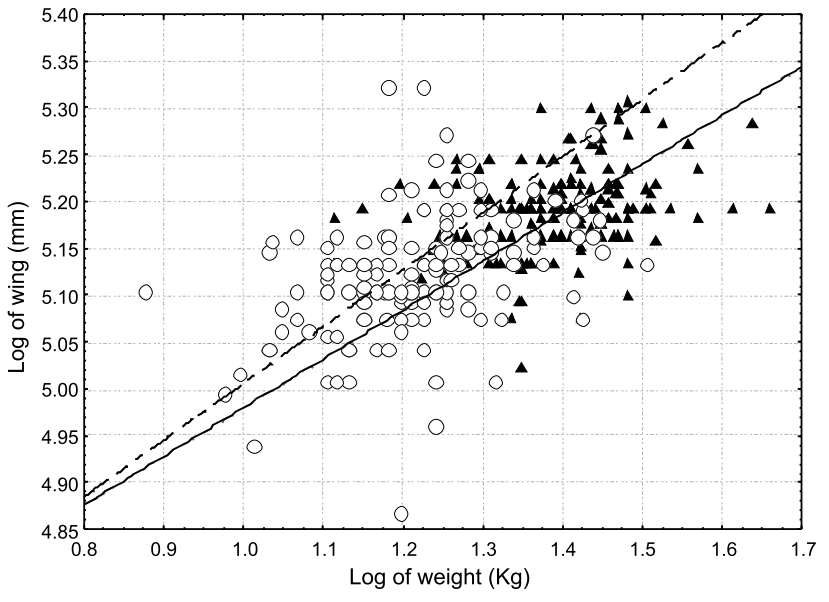

Figure 2. Wing length (tip to metacarpophalangeal articulation) against mass ( $\log _{e}$ transformed) for male and female Coscoroba swans. Scaling lines are plotted for both sexes using RMA regression (females: $y=4.4+0.606^{*} x$, males: $y=4.46+0.52^{*} x$ ). The slopes were not significantly different (Table II), but elevation was significantly greater for females $(p<0.01$, Table III). (O) Females, $(\boldsymbol{\Delta})$ males.

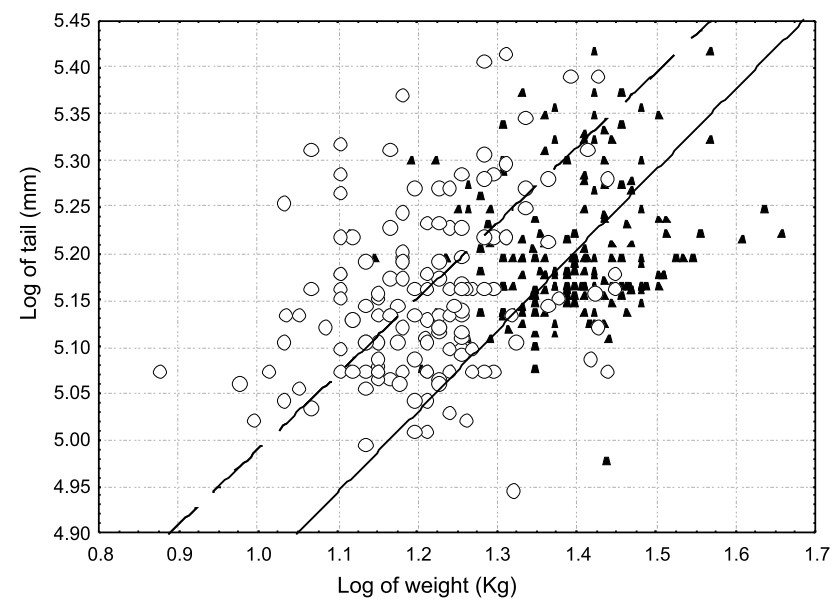

Figure 3. Tail length against mass ( $\log _{\mathrm{e}}$ transformed) for male and female Coscoroba swans. Scaling lines are plotted for both sexes using RMA regression (female: $y=4.11+0.87^{*} x$, males: $y=$ $\left.4.07+0.811^{*} x\right)$. The slopes were not significantly different, but elevation was significantly greater for females $(p<0.001$, Table III). (O) Females, ( $\mathbf{\Delta})$ males.

protection (e.g., Scott 1972,Veselovsky 1973, Hawkins 1986, WhitehEAD \& TSCHIRNER 1990) or owing to the need to defend females against extra-pair copulations (e.g. Mineau \& COOKE 1979, McKinney et al. 1983, Welsh \& Sedinger 1990, Gauthier \& TARdif 1991, Choinière \& Gauthier 1995). As in the Cape Barren goose, male and female coscorobas form long-term pair bonds 
Table I. Means, standard errors and sample sizes for body mass ( $\mathrm{kg}$ ) plus ten morphometric variables (in mm) for the Coscoroba Swan according to sex. Results for univariate ANOVAs between sexes for each measurement are also shown.

\begin{tabular}{|c|c|c|c|c|c|c|c|c|c|c|c|}
\hline \multirow[b]{2}{*}{ Variable } & \multicolumn{2}{|c|}{ Combined } & \multicolumn{3}{|c|}{ Male } & \multicolumn{3}{|c|}{ Female } & \multicolumn{3}{|c|}{ ANOVAs } \\
\hline & Mean & SE & Mean & SE & $\mathrm{N}$ & Mean & SE & $\mathrm{N}$ & $\mathrm{F}$ & df & $p$ \\
\hline MASS & 3.7 & 0.03 & 4.0 & 0.03 & 188 & 3.3 & 0.03 & 154 & 288.5 & 1,340 & $<0.01$ \\
\hline TCU & 68.8 & 0.20 & 70.9 & 0.20 & 189 & 66.1 & 0.24 & 156 & 252.0 & 1,343 & $<0.01$ \\
\hline NOSTRIL & 51.8 & 0.17 & 53.5 & 0.17 & 189 & 49.7 & 0.22 & 156 & 201.7 & 1,343 & $<0.01$ \\
\hline $\mathrm{HBI}$ & 25.3 & 0.08 & 26.1 & 0.09 & 188 & 24.3 & 0.10 & 156 & 196.5 & 1,342 & $<0.01$ \\
\hline WBI & 30.0 & 0.06 & 30.7 & 0.06 & 189 & 29.1 & 0.08 & 156 & 244.8 & 1,343 & $<0.01$ \\
\hline TLH & 136.0 & 0.29 & 139.9 & 0.21 & 189 & 131.1 & 0.27 & 157 & 736.7 & 1,344 & $<0.01$ \\
\hline TARSUS & 101.0 & 0.35 & 105.3 & 0.29 & 189 & 95.6 & 0.35 & 156 & 477.5 & 1,343 & $<0.01$ \\
\hline WING & 174.6 & 0.62 & 179.9 & 0.61 & 188 & 167.9 & 0.91 & 157 & 133.9 & 1,343 & $<0.01$ \\
\hline FOREARM & 206.1 & 0.61 & 213.1 & 0.58 & 188 & 197.5 & 0.67 & 157 & 337.3 & 1,343 & $<0.01$ \\
\hline TAIL & 178.4 & 0.83 & 181.9 & 0.99 & 187 & 173.5 & 1.26 & 152 & 19.4 & 1,337 & $<0.01$ \\
\hline LNE & 336.0 & 1.45 & 351.0 & 1.58 & 187 & 317.9 & 1.66 & 156 & 205.7 & 1,341 & $<0.01$ \\
\hline
\end{tabular}

Table II. Scaling of mature Coscoroba Swan morphometric measurements against body mass using Reduced Major Axis (RMA) regression. The deviation of the RMA slope from that expected under isometry (1/3) was tested for statistical significance for each measurement and sex $\left(T_{1}, T_{2}\right)$ as well as slope difference between sexes $\left(T_{1,2}\right)$.

\begin{tabular}{|c|c|c|c|c|c|c|c|c|c|c|}
\hline \multirow{2}{*}{ Measurement } & \multicolumn{4}{|c|}{ Females $(\mathrm{N}=154)$} & \multicolumn{4}{|c|}{ Males $(\mathrm{N}=188)$} & \multicolumn{2}{|c|}{ Female vs Male slopes } \\
\hline & RMA slope & $\mathrm{R}^{2}$ & Intercept & $\mathrm{T}_{1}$ & RMA slope & $r^{2}$ & Intercept & $\mathrm{T}_{2}$ & $T_{1,2}$ & $\mathrm{p}$ \\
\hline $\mathrm{TCU}$ & 0.405 & 0.138 & 3.70 & 1.00 & 0.439 & 0.009 & 3.65 & 1.45 & 0.34 & 0.210 \\
\hline Nostril & 0.512 & 0.160 & 3.30 & $2.36^{\star \star}$ & 0.481 & 0.007 & 3.31 & $2.02^{*}$ & 0.30 & 0.142 \\
\hline$\left.\mathrm{HBI}\right|^{1,2}$ & 0.478 & 0.050 & 2.60 & 1.85 & 0.514 & 0.018 & 2.55 & $2.48^{* *}$ & 0.33 & 0.760 \\
\hline $\mathrm{WBI}{ }^{1}$ & 0.305 & 0.189 & 3.00 & 0.34 & 0.314 & 0.132 & 2.98 & -0.28 & 0.05 & 0.595 \\
\hline TLH & 0.232 & 0.232 & 4.60 & 1.38 & 0.230 & 0.080 & 4.62 & -1.47 & 0.03 & 0.151 \\
\hline Tarsus & 0.423 & 0.118 & 4.04 & 1.08 & 0.419 & 0.060 & 4.07 & 1.21 & 0.03 & 0.570 \\
\hline Wing $^{2}$ & 0.606 & 0.164 & 4.40 & $3.69^{* * *}$ & 0.520 & 0.103 & 4.46 & $6.68^{* * *}$ & 0.86 & 0.572 \\
\hline Forearm ${ }^{2}$ & 0.388 & 0.152 & 4.82 & 1.17 & 0.413 & 0.068 & 4.80 & 1.13 & 0.25 & 0.438 \\
\hline Tail $^{1,2}$ & 0.867 & 0.084 & 4.11 & $6.85^{\text {***}}$ & 0.811 & 0.035 & 4.07 & $6.60^{* * *}$ & 0.54 & 0.884 \\
\hline
\end{tabular}

${ }^{1}$ for females, $\mathrm{N}=153 ;{ }^{2}$ for males, $\mathrm{N}=187$; Both body mass and the linear measure were $\log _{\mathrm{e}}$ transformed. The deviation of the RMA slope from that expected under isometry $(1 / 3)$ was tested for statistical significance, as was the difference between slopes for the two sexes $\left({ }^{*} p<0,05,{ }^{* *} p<0.01,{ }^{* * *} p<0.001\right)$.

Table III. Differences in elevation between sexes of mature Coscoroba Swan for Reduced Major Axis (RMA) regression of morphometric measurement against body mass ( $\log _{\mathrm{e}}$ transformed). Differences between the sexes in the residuals for a common regression line were tested using a t-test (after WARTON et al. 2006).

\begin{tabular}{|c|c|c|c|c|c|c|c|c|}
\hline \multirow{2}{*}{\multicolumn{2}{|c|}{ RMA regression }} & \multicolumn{7}{|c|}{ Residuals } \\
\hline & & \multicolumn{3}{|c|}{ Males } & \multicolumn{3}{|c|}{ Females } & \multirow[b]{2}{*}{ t-value } \\
\hline Variable (log) & $Y=$ Intercept $+\beta^{\star} X$ & Mean & SE & N & Mean & SE & $\mathrm{N}$ & \\
\hline TCU & $Y=3.7+0.406^{*} X$ & -0.001 & 0.004 & 188 & 0.002 & 0.004 & 154 & 0.54 \\
\hline NOSTRIL & $Y=3.34+0.462 * X$ & -0.003 & 0.004 & 188 & 0.005 & 0.005 & 154 & 1.30 \\
\hline $\mathrm{HBI}$ & $Y=2.64+0.451 * X$ & -0.003 & 0.004 & 187 & 0.006 & 0.005 & 153 & 1.47 \\
\hline WBI & $Y=3.01+0.296^{*} X$ & -0.001 & 0.002 & 188 & 0.002 & 0.003 & 153 & 0.71 \\
\hline TLH & $Y=4.52+0.296^{*} X$ & 0.006 & 0.002 & 188 & -0.006 & 0.002 & 154 & $3.84^{* * *}$ \\
\hline TARSUS & $Y=3.99+0.476^{*} X$ & 0.003 & 0.004 & 188 & -0.007 & 0.004 & 154 & 1.83 \\
\hline WING & $Y=4.52+0.489 * X$ & -0.009 & 0.004 & 187 & 0.009 & 0.005 & 154 & $2.93^{\star *}$ \\
\hline FOREARM & $Y=4.79+0.409 * X$ & 0.003 & 0.003 & 187 & -0.001 & 0.004 & 154 & 0.61 \\
\hline TAIL & $Y=4.36+0.625^{\star} X$ & -0.032 & 0.006 & 186 & 0.040 & 0.008 & 150 & $7.53^{\star \star \star}$ \\
\hline
\end{tabular}

** $p<0.01,{ }^{* * *} p<0.001$ 
and look after their goslings. The male is primarily a guardian and helps with nest building but not with incubation.

Positive allometry is most likely to evolve when an increase in relative trait size leads to a greater mating success for larger individuals (BondurIANSKY 2007). Dimorphic, sexually selected characters tend to have positively allometric slopes (GREEN 1992, Kodric-Brown et al. 2006). Thus, scaling relationships have been proposed as a potential means to distinguish between sexual and natural selection as causes of dimorphism (GREEN 2000).

However, according to more recent research, a link between sexual selection and positive allometry only seems clear for exaggerated sexual characters (e.g., tails of peacocks or widowbirds) of the kind absent in Coscoroba swans. A recent review of less extreme secondary sexual characters suggested that sexual selection does not consistently result in positive allometry, and that nonsexual traits sometimes show positive allometry (BONDURIANSKY 2007). Various mechanisms have been proposed which could generate such a wide diversity of allometries for both sexual and non-sexual characters, although there is currently a general lack of empirical data to distinguish between them (Bonduriansky 2007). Cuervo \& Møller (2009) showed that ornamental feathers tend to have particularly high allometric slopes. However, non-ornamental tail feathers also tended to be positively allometric (although to a lesser extent), and Cuervo \& MølLer (2009) support the view of Bonduriansky (2007) that positive allometry should not be considered as diagnostic of a sexually selected character.

This study extends the currently limited knowledge on scaling patterns in Anatidae (Green 2000, Green et al. 2001) and shows that positive allometry can be observed in monomorphic species in characters which have never been considered as ornaments. The limited data available suggests that, amongst the Anatidae, allometries do not appear to show consistent patterns. For example, head length is isometric in the Coscoroba Swan, negatively allometric in the Eurasian Teal Anas crecca Linnaeus, 1758 (Green et al. 2001), and positively allometric in male Marbled Teal, Marmaronetta angustirostris (Ménétries, 1832) (GREen 2000).

There is little evidence available from field studies to assess the role of sexual selection in explaining the limited sexual dimorphism and positive allometry recorded in the Coscoroba Swan. Although this is a monogamous species, increasing the size of some attributes may confer some advantage for mate selection or male-male competition. The tail appears crucial when pivoting and to enable the "up-ending" or "tipping" feeding technique regularly used by this species, but it may also be a sexually selected character important for signalling. Wings are used in male-male combat (authors, pers. obs.) but wing growth is most likely to be constrained by the biomechanics of flight. Across the Anatidae, folded wing (a different measure of wing than ours) shows positive interspecific allometry (GREen et al. 2001), as does wingspan for all flying birds (RAYNER 1985). This is consistent with a possible biomechanical expla- nation for the positive allometry for wing in Coscoroba. Tail morphology may also be an adaptation to biomechanics (MATYJASIAK et al. 2009).

Although female Coscoroba swans have relatively longer wings and tails for a given mass, we have no other reason to believe they are subject to greater sexual selection than males. The measures of nostril and height of the bill should mainly reflect bill adaptations for feeding (see Ferns et al. 2005), although the bill may also have a significant courtship role since the Coscoroba Swan has displays based on head movements (see HorRocks et al. 2009), and perhaps breathing during flight might influence bill morphology. However, further research is required to establish the importance of the different characters addressed in this study for mate choice, foraging ecology etc in this species.

We used body mass as an overall measure of structural size (Peig \& Green 2009), but mass typically changes during wing moult, increasing in some Anatidae but decreasing in others (Hohman et al. 1992). There is no information as yet on seasonal changes in body mass in Coscoroba Swan. Such changes can even vary between the sexes (Hohman et al. 1992), such that it is feasible that our analyses of elevation (Table III) would give different results at a different stage of the annual cycle. However, the finding that females have relatively shorter heads compared with their wings and tails would not change.

Contrary to Green (2000), we suggest that positively allometric slopes alone should not be considered as evidence for sexual selection of the considered traits. Nevertheless, more studies such as ours are required before we can begin to understand the conditions that generate negative allometry, positive allometry or isometry in birds (see BONDURIANSKY 2007, Cuervo \& Møller 2009 for more discussion).

\section{ACKNOWLEDGEMENTS}

We thank R. Tavares, J. Camacho, and L. Bassini from LEGA, Universidade Federal de Pelotas, RS, Brazil for invaluable technical help in carrying out DNA extraction. J. Peig provided helpful discussion. To an anonymous referee for the comments that substantially improved this manuscript.

\section{LITERATURE CITED}

Arnold, T.W. \& A.J. Green. 2007. On the allometric relationship between size and composition of avian eggs: a reassessment. Condor 109 (3): 705-714. doi:10.1650/7902.1.

BONDURIANSKY, R. 2007. Sexual selection and allometry: a critical reappraisal of the evidence and ideas. Evolution 61 (4): 838849. doi: 10.1111/j.1558-5646.2007.00081.x.

Calabuig, C.P.; A.J. Green, M. Ferrer, R. Muriel \& H. Moreira. 2011. Sexual size dimorphism and sex determination by morphometric measurements in the Coscoroba Swan. Studies on Neotropical Fauna and Environment 46: 177-184. doi: 10.1080/01650521.2011.617545. 
Calabuig, C.P.; A.J. Green; J.O. Menegheti; R. Muriel \& J. Patino. 2010. Fenología del coscoroba (Coscorobacoscoroba) en el sur de Brasil y sus movimientos hacia Argentina. Ornitología Neotropical 21: 555-566.

CHoInière, L. \& G. GauthiER. 1995. Energetics of reproduction in female and male Greater Snow Geese. Oecologia 103: 379-389.

Clutton-Brock, T.H. \& G.A. Parker. 1992. Potential reproductive rates and the operation of sexual selection. The Quaterly Review of Biology 67 (4): 437-456.

Clutton-Brock, T.H. \& A.C.J. Vincent. 1991. Sexual selection and the potential reproductive rates of males and females. Nature 351: 58-60. doi:10.1038/351058a0.

Cuervo, J.J. \& A.P. Møller. 2009. The allometric pattern of sexually size dimorphic feather ornaments and factors affecting allometry. Journal of Evolutionary Biology 22 (7): 1503-1515. doi: 10.1111/j.1420-9101.2009.01758.x.

Donne-Goussé, C.; V. Laudet \& C. Hanni. 2002. A molecular phylogeny of Anseriformes based on mitochondrial DNA analysis. Molecular Phylogenetics and Evolution 23 (3): 339-356. doi:10.1016/S1055-7903(02)00019-2.

Ferns, P.N.; J.P. Reed; E.D. GregG; C. O’Hara; A. Lang \& G.R. Sinkowski. 2005. Bill knob size and reproductive effort in Common Shelducks Tadorna tadorna. Wildfowl 55: 47-57.

Ferrer, M. \& C. De Le Court. 1992. Sex identification in the Spanish Imperial Eagle. Journal of Field Ornithology 62: 359-364.

Figuerola, J. \& A.J. Green. 2000. The evolution of sexual dimorphism in relation to mating patterns, nesting behavior, insularity and sympatry in the Anseriformes. Functional Ecology 14: 701-710. doi:10.1046/j.1365-2435.2000.00474.x.

GAUTHIER, G. \& J. TARDIF. 1991. Female feeding and male vigilance during nesting in greater snow geese. The Condor 93: 701-711.

Gould, S.J. 1966. Allometry and size in ontogeny and phylogeny. Biological Reviews 41 (4): 587-640. doi:10.1111/j.1469. 185X.1966.tb01624.X

Green, A.J. 1992. Positive allometry is likely with mate choice, competitive display and other functions. Animal Behaviour 43 (1): 170-172.

Green, A.J. 2000. The scaling and selection of sexually dimorphic characters: an example using the Marbled Teal. Journal of Avian Biology 31 (3): 345-350. doi:10.1034/ j.1600-048X.2000.310310.x.

Green, A.J.; J. Figuerola \& R. King. 2001. Comparing evolutionary and static allometry in the Anatidae. Journal of Ornithology 142 (3): 321-334. doi:10.1007/BF01651371.

HawKINS, L.L. 1986. Nesting behaviour of male and female whistling swans and implications of male incubation. Wildfowl 37: 5-27.

Hohman, W.L.; C. D. Ankney \& D.H. Gordon. 1992. Ecology and management of postbreeding waterfowl. Ecology and Management of Breeding Waterfowl: 128-189.

Horrocks, N.; C. Perrins \& A. Charmantier. 2009. Seasonal changes in male and female bill knob size in the mute swan Cygnus olor. Journal of Avian Biology 40: 511-519. doi:10.1111/j.1600-048X.2008.04515.x.
Johnstone, R.A.; J.D. Reynolds \& J.C. Deutsch. 1996. Mutual mate choice and sex differences in choosiness. Evolution 50 (4): 1382-1391.

Kear, J. 2005. Ducks, Geese and Swans. Oxford, University Press, vol. 1, 908p.

Kodric-Brown, A.; R.M. Sibly \& J.H. Brown. 2006. The allometry of ornaments and weapons. Proceedings of the National Academy of Sciences of the United States of America 103 (23): 8733-8738. doi:10.1073/pnas.0602994103.

Kraajeveld, K.; J. Gregurke; C. Hall; J. Komdeur \& R.A. Mulder. 2004. Mutual ornamentation, sexual selection, and social dominance in the black swan. Behavioral Ecology 15 (3): 380-389. doi: 10.1093/beheco/arh023.

Matyjasiak, P.; A. Marzal; C. Navarro; F. de Lope \& A.P. Moller. 2009. Fine morphology of experimental tail streamers and flight manoeuvrability in the house martin Delichon urbica. Functional Ecology 23: 389-396.

McArdLE, B.H. 1988. The structural relationship: regression in biology. Canadian Journal of Zoology 66 (11): 2329-2339. doi: 10.1139/z88-348.

McKinney, F.; S.R. Derrickson \& P. Mineau. 1983. Forced copulation in waterfowl. Behaviour 86 (3/4): 250-294.

Miller, S.L.; M.A. GregG, A.R. Kuritsubo; S.M. Combs; M.K. Murdock; J.A. Nilsson; B.R. Noon \& R.G. Botzler. 1988. Morphometric variation in tundra swans: relationships among sex and age classes. The Condor 90: 802-815.

Mineau, P. \& F. Cooke. 1979. Territoriality in Snow Geese or the protection of parenthood-Ryder's and Inglis's hypothesis re-assessed. Wildfowl 30: 16-19.

Peig, J. \& A.J. Green. 2009. New perspectives for estimating body condition from mass/length data: the scaled mass index as an alternative method. Oikos 118: 1883-1891. doi: 10.1111/ j.1600-0706.2009.17643.x.

RAYNER, J.M.V. 1985. Linear Relations in Biomechanics - the Statistics of Scaling Functions. Journal of Zoology 206: 415-439.

Reiss, M.J. 1991. The Allometry of Growth and Reproduction. Cambridge, University Press, 200p. doi:10.1017/СBO9780511 608483.

ScotT, P. 1972. The swans. London, Michael Joseph, 298p.

Veselovsky, Z. 1973. The breeding biology of Cape Barren geese Cereopsis novaehollandiae. International Zoo Yearbook 13 (1): 48-55. doi:10.1111/j.1748-1090.1973.tb02101.x.

Warton, D.I.; I.J. Wright; D.S. Falster \& M. Westoby. 2006. Bivariate line-fitting methods for allometry. Biological Reviews 81 (2): 259-291. doi:10.1017/S1464793106007007.

Welsh, D. \& J.S. Sedinger. 1990. Extra-pair copulations in black brant. The Condor 92: 242-244.

WhiteheAd, P.J. \& K. Tschirner. 1990. Eggs and hatchlings of the magpie goose Anseranas semipalmata. Emu 90 (3): 154-160.

Submitted: 09.VIII.2012; Accepted: 25.III.2013.

Editorial responsibility: Mauricio O. Moura 